\title{
Adaptability and Stability of Cotton Genotypes Regarding Fiber Yield and Quality Traits
}

\author{
Paulo Eduardo Teodoro,^ Francisco José Correia Farias, Luiz Paulo de Carvalho, Larissa Pereira Ribeiro, \\ Moysés Nascimento, Camila Ferreira Azevedo, Cosme Damião Cruz, and Leonardo Lopes Bhering
}

\begin{abstract}
The performance of textile processes and the quality of the products depends on the several cotton (Gossypium hirsutum L.) fiber quality traits, such as micronaire index, fiber length, and fiber strength. This research aims to recommend cotton genotypes for the Brazilian Cerrado based on fiber yield and fiber quality traits. Nineteen cotton cultivar variety trials were performed in the 2013-2014 and 2014-2015 crop seasons. Each trial was conducted as a randomized complete block design with 12 treatments and four replications. The evaluated traits were fiber yield, fiber length, fiber strength, and micronaire. For each trait, a modified Lin and Binns method was used to recommend the best genotypes for all environments (favorable and unfavorable). This method was also used in a multivariate manner, aiming at a general recommendation of genotypes based on the multiple traits evaluated. The genotype $x$ environment interaction was significant for all evaluated traits. Genotypes with high adaptability and stability were identified for each trait. The multivariate method identified IMA 08 WS and BRS 335 as the genotypes that had the best combination of main desirable traits. The analysis further revealed that new crosses could be performed between genotypes with high yield adaptability and stability and genotypes with adequate fiber quality traits.
\end{abstract}

P.E. Teodoro, Federal Univ. of Mato Grosso do Sul, Campus of Chapadão do Sul, Chapadão do Sul, 75560-000, Mato Grosso do Sul, Brazil; F.J.C. Farias and L.P. de Carvalho, Embrapa Cotton, Campina Grande, 58428-095, Paraíba, Brazil; L.P. Ribeiro, M. Nascimento, C.F. Azevedo, C.D. Cruz, and L.L. Bhering, Federal Univ. of Viçosa, Viçosa, 85560-000, Minas Gerais, Brazil. Received 13 Apr. 2018. Accepted 6 Dec. 2018. `Corresponding author (eduteodoro@hotmail. com). Assigned to Associate Editor Lucia Gutierrez.

Abbreviations: FL, fiber length; FS, fiber strength; FY, fiber yield; $\mathrm{G} \times \mathrm{E}$, genotype $\times$ environment interaction.

$\mathrm{T}$ HE performance of textile processes and the quality of the products depends on cotton (Gossypium hirsutum L.) fiber quality traits, such as micronaire index, fiber length (FL), and fiber strength (FS) ( $\mathrm{Ng}$ et al., 2013). Cotton genotypes with a micronaire index between 3.8 and 4.2, a long FL, and high FS prevent yarn twisting, are ideal for increasing the efficiency of spinning machines, and result in a softer, bulky, flexible, and malleable fabric (Freire, 2015). To become competitive in the US-dominated global cotton market, Brazilian breeding programs seek to select genotypes with high fiber yield (FY) and desirable fiber quality traits, such as premium micronaire, a long FL, and a high FS.

The great diversity in upland cotton (G. hirsutum subsp. latifolium Hutch.) allows it to be cultivated in two regions of Brazil (Central-West and Northeast). The magnitude of genotype $\times$ environment interaction $(\mathrm{G} \times \mathrm{E})$ across most traits complicates selecting the best variety. Yield stability was reported as the second most important criterion for selecting parents for hybridization in public and private breeding programs in the United States (Campbell and Jones, 2005). However, the $\mathrm{G} \times \mathrm{E}$ interaction affects both the selection of superior genotypes and fiber quality traits, as demonstrated by Carvalho et al. (2015).

Published in Crop Sci. 59:518-524 (2019).

doi: $10.2135 /$ cropsci2018.04.0250

(C) Crop Science Society of America | 5585 Guilford Rd., Madison, WI 53711 USA All rights reserved. 
To understand the nature of the $\mathrm{G} \times \mathrm{E}$ interaction it is necessary to evaluate multiple genotypes at several sites and or cropping seasons. As a result, Embrapa Cotton has divided its experimental network into two mega-environments: Cerrado and Semiarid, predominant biomes in the Central-West and Northeast Regions, respectively. Conab (2017) reported that Brazilian cotton cultivation is concentrated in the Cerrado. This biome occupies $\sim 22 \%$ of the national territory and has peculiar climatic characteristics along its extension in terms of rainfall, temperature, and relative air humidity, as well as different types of soil. Therefore, analyses of adaptability and phenotypic stability must be performed to identify genotypes with predictable behavior that are responsive to environmental variations in specific or broad-sense conditions (Cruz et al., 2012).

Currently, several methods have been made available to evaluate a group of genotypes tested in multiple environments. In the Lin and Binns (1988) method, the parameter $P_{i}$ is estimated based on the mean square of the distance between the genotype mean and the maximum mean response obtained in the environment. This parameter has a variance property and measures the response of a genotype in relation to the best genotype in each environment. Carneiro (1998) modified this methodology by decomposing the estimator $P_{i}$ into parts due to favorable and unfavorable environments. Additionally, he proposed that the $P_{i}$ be estimated assuming a hypothetical ideal genotype as the maximum response, defined by Verma et al. (1978) as the least responsive genotype to unfavorable environments, but responsive to favorable conditions. Thus, genotypes with lower estimates are less distant from the ideal genotype and are adapted and stable, simultaneously.

The modifications incorporated by Carneiro (1998) make this method a valuable tool to classify and discriminate the genotypes, and they have been used in several studies (Murakami et al., 2004, Amorim et al., 2006, Franceschi et al., 2010). Furthermore, $P_{i}$ can be estimated in the multivariate context by standardizing and adding the $P_{i}$ of each trait, enabling genotypes to be recommended based on multiple traits of interest. These modifications make it possible to apply this method for multiple traits and to make more precise and simplified recommendations to cotton growers.

The recommendation of cotton genotypes based on multiple traits has been made differently until now. Researchers have generated super-traits, which consist of linear combinations between various quality traits. In Louisiana, Blanche and Myers (2006) proposed a selection index composed of weights of 0.60 for cotton lint yield and 0.40 for FL. Their index has the merits of being simple, but some important traits such as FS and micronaire were excluded. Bourland et al. (2010) focused solely on fiber quality traits in the development of the $Q$-score index.
In cotton cultivar evaluation trials in Spain, Baxevanos et al. (2008) adopted a more complete selection index where selection index $(\mathrm{SI})=0.6($ yield $)+0.1($ lint percentage $+\mathrm{FL}$ $+\mathrm{FS})+0.05$ (uniformity + elongation), in which micronaire remained ignored. Besides, lint percentage is highly correlated with lint yield (Farias et al., 2016), so it can be argued that there was some redundancy in the formula. In the national cotton registration standards currently implemented in China, the selection index can be presented as a linear combination (Xu et al., 2017): SI $=-0.17(\mathrm{FL})$ $+0.30(\mathrm{FS})-0.19$ (micronaire) +0.93 (yield) +0.14 (lint percentage). In this index, negative weights were given to traits known for their negative correlations with yield (FL and micronaire), implying much more emphasis on yield.

The main criticism of creating indices such as those reported above is that the $\mathrm{G} \times \mathrm{E}$ interaction of multiple traits is investigated in a single trait index. In this way, the results are influenced mainly by the feature with greater weight in the index, and this can compromise the recommendation. Thus, this study aimed to identify and recommend cotton genotypes for the Brazilian Cerrado based on yield adaptability and stability; to identify cotton genotypes that present high adaptability and stability for fiber quality; and to verify the possibility of recommendation of genotypes that have high adaptability and stability for FY and quality simultaneously.

\section{MATERIALS AND METHODS}

Nineteen variety trials of cotton cultivars were performed across the 2013-2014 and 2014-2015 cropping seasons. The environments consisted of the combinations between sites and cropping seasons of Brazilian Cerrado, whose edaphoclimatic characteristics are expressed in Table 1. The trial consisted of a randomized complete block design with 12 treatments (cotton cultivars TMG 41 WS, TMG 43 WS, IMA CV 690, IMA 5675 B2RF, IMA 08 WS, NUOPAL, Delta Pine DP 555 BGRR, DELTA OPAL, and Embrapa cultivars BRS 286, BRS 335, BRS 368 RF, and BRS 369 RF) and four replications. The genotypes used in all the trials have a medium maturity (between 140 and $150 \mathrm{~d}$ ) and are recommended for cultivation in the Brazilian Cerrado.

The plots consisted of four 5.0-m rows, spaced at $0.90 \mathrm{~m}$ between rows, with nine plants per meter in each row. The plots were managed according to the local production recommendations of each test site. In each plot, 20 representative bolls were collected at maturity to determine the FL (mm), FS (gf tex $^{-1}$ ), and fiber fineness in micronaire, using a high volume instrument (HVI). Cotton seed yield was evaluated in the two central rows by mechanically harvesting $4 \mathrm{~m}$ of each line, scattering $0.5 \mathrm{~m}$ at each end of the plot (border), correcting to $13 \%$ of moisture, and extrapolating to kilograms per hectare. A sample of each plot was used to determine the fiber percentage of each sample unit. After, the FY was estimated by the multiplication between cotton seed yield and fiber percentage.

First, individual analyses of variance were performed for each environment. After verifying the homogeneity between 
Table 1. Abbreviations, geographic coordinates, and climatic characteristics of cotton variety test sites $\dagger$ evaluated for environmental impact in the Brazilian Cerrado.

\begin{tabular}{|c|c|c|c|c|c|c|c|c|}
\hline Environment, state & Abbreviation & $\begin{array}{l}\text { Cropping } \\
\text { season }\end{array}$ & Altitude & Latitude & Longitude & Rainfall & $\begin{array}{c}\text { Avg. } \\
\text { temperature }\end{array}$ & $\begin{array}{c}\text { Climate } \\
\text { type§ }\end{array}$ \\
\hline & & & $m$ & ${ }^{\circ} \mathrm{S}$ & ${ }^{\circ} \mathrm{W}$ & $\mathrm{mm}$ & ${ }^{\circ} \mathrm{C}$ & \\
\hline Trindade, MG & TRI & 2013-2014 & 927 & 21.06 & 44.10 & 880 & 26.2 & Aw \\
\hline \multirow[t]{2}{*}{ Santa Helena de Goiás, GO } & SHE1 & 2013-2014 & 562 & 17.48 & 50.35 & 661 & 27.1 & Aw \\
\hline & SHE2 & 2014-2015 & & & & 642 & 26.8 & \\
\hline \multirow[t]{4}{*}{ Primavera do Leste, MT } & PVA1 & 2013-2014 & 465 & 15.33 & 54.17 & 601 & 27.5 & Aw \\
\hline & PVA2 & 2014-2015 & & & & 615 & 27.1 & \\
\hline & PVA3 & 2014-2015 & & & & 625 & 26.9 & \\
\hline & PVA4 & 2014-2015 & & & & 638 & 26.9 & \\
\hline \multirow[t]{2}{*}{ Campo Verde, MT } & CV1 & 2013-2014 & 736 & 15.32 & 55.10 & 864 & 25.8 & Af \\
\hline & CV2 & 2014-2015 & & & & 879 & 25.4 & \\
\hline Sinop, MT & $\mathrm{SIN}$ & 2013-2014 & 345 & 11.51 & 55.30 & 409 & 30.9 & Aw \\
\hline \multirow[t]{2}{*}{ Pedra Preta, MT } & PPA1 & 2013-2014 & 248 & 16.37 & 54.28 & 849 & 26.0 & Bsh \\
\hline & PPA2 & 2014-2015 & & & & 840 & 26.2 & \\
\hline Luís Eduardo Magalhães, BA & LEM & 2013-2014 & 769 & 12.5 & 45.47 & 802 & 25.4 & Aw \\
\hline São Desidério, BA & SDES & 2013-2014 & 497 & 12.21 & 44.58 & 658 & 27.0 & Aw \\
\hline Montividiu, GO & MON & 2013-2014 & 821 & 17.26 & 51.10 & 455 & 30.1 & Aw \\
\hline Magalhães de Almeida, MA & MAG & 2013-2014 & 36 & 03.23 & 42.12 & 817 & 26.8 & Aw \\
\hline Teresina, PI & TER & 2013-2014 & 72 & 05.05 & 42.48 & 810 & 26.8 & Aw \\
\hline Chapadão do Sul, MS & $\mathrm{CHA}$ & 2014-2015 & 800 & 18.47 & 52.37 & 898 & 26.7 & Aw \\
\hline Sorriso, MT & SOR & 2014-2015 & 365 & 12.32 & 55.42 & 436 & 31.2 & Aw \\
\hline
\end{tabular}

† Data obtained by the National Institute of Meteorology (INPE).

‡ State abbreviations: MG, Minas Gerais; GO, Goiás; MT, Mato Grosso; BA, Bahia; MA, Maranhão; PI, Piauí; MS, Mato Grasso do Sul.

$\S$ According to the Köppen classification; Af, tropical rainforest; Aw, tropical wet-dry savanna; Bsh, arid steppe hot.

variances throughout the environments, the joint ANOVA was performed based on the statistical model described below:

$$
Y_{i j k}=\mu+E_{j}+\mathrm{B} / \mathrm{E}_{j k}+G_{i}+\mathrm{G} \times \mathrm{E}_{i j}+e_{i j k}[1]
$$

where $Y_{i j k}$ is the observation in the $k$ th block, evaluated in the $i$ th genotype and $j$ th environment; $\mu$ is the overall mean; $\mathrm{B} / \mathrm{E}_{j k}$ is the effect of block $k$ within environment $j ; G_{i}$ is the effect of the $i$ th genotype, considered as fixed; $E_{j}$ is the effect of the $j$ th environment, considered as random; $\mathrm{G} \times \mathrm{E}_{i j}$ is the random effect of the genotype $i \times$ environment $j$ interaction; and $e_{i j k}$ is the random error associated with the $Y_{i j k}$ observation.

The environmental index $\left(I_{j}\right)$ was estimated for each environment and trait, according to Eq. [2] proposed by Finlay and Wilkinson (1963). Negative values of $I_{j}$ indicate unfavorable environments, whereas positive values designate favorable environments.

$$
I_{j}=\frac{\sum_{i} Y_{i j}}{g}=\frac{\sum_{i} \sum_{j} Y_{i j}}{g e}
$$

where $Y_{i j}$ is the yield of the $i$ th genotype in the $j$ th environment, $g$ is the number of genotypes, and $e$ is the number of environments. Results are presented in Supplemental Table S1.

For each trait, adaptability and stability were evaluated by the Lin and Binns (1988) method, as modified by Carneiro (1998). In this method, the general recommendation is based on the lower estimates of the parameter $P_{i}$ for each trait, according to Eq. [3]:

$$
P_{i}=\frac{\sum_{j=1}^{e}\left(Y_{i j}-Y_{m j}\right)^{2}}{2 e}
$$

where $Y_{m j}$ is the estimate of the hypothetical ideal genotype trait in environment $j$, based on Cruz et al. (1989) (Eq. [4]):

$$
Y_{m j}=\beta_{0}+\beta_{1} I_{j}+\beta_{2} T\left(I_{j}\right)
$$

where $\beta_{0}$ is the maximum value observed for the traits FY, FL, and FS; for micronaire, this value was defined as 4.0 (USDA-AMS, 2001). For FY, FL, and FS, the values of $\beta_{1}$ and $\beta_{1}+\beta_{2}$ were defined as 0.5 (less responsive to unfavorable environments) and 1.5 (responsive to favorable environments), respectively. For micronaire, the values of $\beta_{1}$ and $\beta_{2}$ were defined as 0 , since the ideal value is 4.0 in any environment; $I_{j}$ is the coded environmental index; $T\left(I_{j}\right)=0$ if $I_{j}<0$; and $T\left(I_{j}\right)=I_{j}-I_{+}$if $I_{j}>0$, where $I_{+}$is the mean of the positive indices.

For the favorable $\left(P_{\text {if }}\right)$ and unfavorable $\left(P_{\text {id }}\right)$ environments, adaptability and stability were estimated according to Eq. [5] and [6], respectively:

$$
\begin{gathered}
P_{\text {if }}=\frac{\sum_{j=1}^{f}\left(Y_{i j}-Y_{m j}\right)^{2}}{2 f} \\
P_{\text {id }}=\frac{\sum_{j=1}^{d}\left(Y_{i j}-Y_{m j}\right)^{2}}{2 d}
\end{gathered}
$$

where $f$ is the number of favorable environments, $d$ is the number of unfavorable environments, based on Finlay and Wilkinson (1963). 
Finally, the multivariate parameters of adaptability and stability considering FY, FL, FS, and micronaire simultaneously for the set of environments $\left(P_{\text {im }}\right)$ were estimated by Eq. [7]:

$$
P_{i m}=\sum_{k=1}^{v}\left(\frac{P_{i k}}{\hat{\sigma}_{P i k}}\right) \frac{1}{p_{k}}
$$

where $P_{i k}$ is the univariate estimator of the adaptability and stability of the $i$ th genotype associated with the $k$ th trait, $\hat{\sigma}_{P i k}$ is the SD of $P_{i k}$, and $p_{k}$ is the weight assigned to the $k$ th trait. In this case, the values of 10, 1.0, 2.0, and 1.5 were considered for the traits FY, FL, FS, and micronaire, respectively. These weights were based on perceived demands of the current cotton market, and are particularly weighted in favor of fibers desirable for ring-spinning technology (Freire, 2015). Similar procedure was adopted by Bourland et al. (2010); however, yield was not considered in this index. All analyses were performed in the Genes software (Cruz, 2013).

\section{RESULTS AND DISCUSSION Joint ANOVA}

Genotypes presented a significant effect $(p \leq 0.05)$ in all evaluated environments for all traits (Supplemental Tables S1, S2, $\mathrm{S} 3$, and S4). The coefficients of variation obtained in the individual ANOVA were $<16 \%$, leading to a high experimental precision $(<10 \%)$ in the joint ANOVA (Table 2 ), according to Pimentel-Gomes (2009). This estimate was lower than that reported by other authors that investigated the $\mathrm{G} \times \mathrm{E}$ interaction in cotton in Brazilian environments (Souza et al., 2006; Silva Filho et al., 2008; Farias et al., 2016).

In the joint ANOVA (Table 2), genotypes, environments, and $\mathrm{G} \times \mathrm{E}$ interaction presented a significant effect $(p \leq 0.05)$ for all traits. Significant $\mathrm{G} \times \mathrm{E}$ interaction for FY in Mato Grosso had been previously verified by Souza et al. (2006), Suinaga et al. (2006), and Farias et al. (2016). Similar results were observed by other authors in studies on cotton agronomic and fiber quality traits (Campbell and Jones, 2005; Baxevanos et al., 2008, Ng et al., 2013, Carvalho et al., 2015, Farias et al., 2016).

Genotype $\times$ environment interaction is one of the bottlenecks of plant breeding, since it hinders the generalized of recommendation a genotype to several environments. This result can be explained by differences between environments regarding altitude, latitude, longitude, temperature, rainfall, and humidity (Table 1) and crop management. Regarding the fiber quality traits, high temperatures can result in shorter fibers and increased micronaire (Reddy et al., 1991), reducing the quality delivered to the textile industry.

\section{Yield Adaptability and Stability}

Yield adaptability and stability estimates by the Lin and Binns (1988) method, as modified by Carneiro (1998), are given in Table 3. The genotypes recommended based on the lower estimates of $P_{i}$ for the total set of environments and favorable environments that have a positive environmental index according to Finlay and Wilkinson (1963) (Supplemental Table S5) were IMA CV 690, DP 555 BGRR, and BRS 369 RF. These genotypes presented the highest mean across 19 environments evaluated in this work. The correlation between the estimates of general $P_{i}$ and favorable $P_{i}$ was high $(0.88)$ and shows that genotypes responsive to highly favorable environments can be widely recommended for the Brazilian Cerrado.

For unfavorable environments (Supplemental Table S5), the best genotypes were IMA 08 WS, IMA CV 690, and DP 555 BGRR (Table 3). These last two were also recommended in a generalized way and for favorable environments. Results demonstrate that the genotypes IMA CV 690 and DP 555 BGRR are the closest to the hypothetical ideal genotype defined by Verma et al. (1978), meaning they present good yield in unfavorable environments and are responsive to improvements in the environments. These cultivars have high genetic distance based on agronomic traits and fiber quality (Gilio et al., 2017), which allows transgressive genotypes for lint yield to be selected for FY.

Cotton is one of the crops with the highest production cost in the Brazilian Cerrado. This is due to the complex of pests and diseases, such as false mildew (Ramularia areola), ramulose (Colletotrichum gossypii var. cephalosporioides), and boll weevil (Anthonomus grandis), making it necessary to apply pesticides in a preventive way (Freire, 2015). Therefore, the identification of genotypes with yield stability for favorable environments (Supplemental Table S5) that respond to intensive crop management is of interest to

Table 2. Joint analysis for fiber yield (FY), (FL), fiber strength (FR), and micronaire of 12 early cotton genotypes evaluated in 19 Brazilian Cerrado environments in the 2013-2014 and 2014-2015 cropping seasons.

\begin{tabular}{|c|c|c|c|c|c|}
\hline \multirow[b]{2}{*}{ Source of variation } & \multirow[b]{2}{*}{ df } & \multicolumn{4}{|c|}{ Mean squares } \\
\hline & & FY & FL & FS & Micronaire \\
\hline & & $\mathrm{kg} \mathrm{ha}^{-1}$ & $\mathrm{~mm}$ & gf tex ${ }^{-1}$ & \\
\hline Environments (E) & 18 & $10,599,770.42^{*}$ & $35.19^{\star}$ & $81.25^{\star}$ & $5.92^{*}$ \\
\hline Blocks/environments & 57 & $42,223.61$ & 0.72 & 2.17 & 0.04 \\
\hline Genotypes (G) & 11 & $714,991.03^{*}$ & $23.80^{*}$ & $83.14^{*}$ & $1.79^{*}$ \\
\hline $\mathrm{G} \times \mathrm{E}$ & 198 & $198,986.84^{\star}$ & $1.07^{*}$ & $4.98^{\star}$ & $0.14^{*}$ \\
\hline Residual & 627 & $27,348.60$ & 0.58 & 1.68 & 0.04 \\
\hline Mean & - & $1,750.08$ & 29.80 & 30.31 & 4.27 \\
\hline $\mathrm{CV}(\%)$ & - & 9.45 & 2.56 & 4.28 & 4.66 \\
\hline
\end{tabular}

* Significant at the 0.05 probability level. 
breeding programs. This work revealed that genotypes IMA CV 690 and DP 555 BGRR could be cultivated in all environments evaluated when considering FY.

Although cotton is cultivated under high management inputs, which hypothetically characterizes a favorable environment, the use of soybean [Glycine max (L.) Merr.]-cotton double crop has increased in the Cerrado. In regional farms, soybean genotypes are sown in the first crop season (i.e., early October) and harvested in late January. Subsequently, cotton genotypes are sown in the second crop season and harvested in late July. Freire (2015) points out that cotton genotypes cultivated in the second crop season are subject to water stress at the flowering stage and cloud cover at the boll formation stage. These are the main limiting factors for cotton development. Therefore, the genotype IMA 08 WS is a promising alternative for cotton farmers that use soybean-cotton succession in the Brazilian Cerrado, since it is more adaptable to and stable in unfavorable environments.

\section{Adaptability and Stability of Fiber Quality}

Table 4 shows that genotypes with a long FL (IMA 08 WS and BRS 335) were recommended in a generalized way for favorable and unfavorable environments, since they presented the lowest $P_{i}$ estimates. Similar behavior was observed for FS (Table 5), where the TMG 41 WS and DELTA OPAL genotypes obtained the highest mean values across environments and were recommended in a generalized way for favorable and unfavorable environments. Identifying cotton genotypes that have adaptability and stability for FL and FS is important if production is to meet the needs of the textile industry. The best genotypes for these traits presented the highest mean across environments and can be cultivated in favorable and unfavorable environments and in a generalized way for the whole set of environments.

Micronaire is related to fibers maturity and fineness and is linearly related to the photosynthesis of the canopy, which occurs between 15 and $45 \mathrm{~d}$ after flowering (Bauer et al., 2000 ), and is sensitive to environmental variations, notably high temperatures. The genotypes IMA 5675 B2RF and BRS 335 presented micronaire overall means within the standard required by the textile industry (between 3.8 and 4.2 ) and were recommended in a generalized way for favorable and unfavorable environments (Table 6). These are relevant results since, in favorable environments, values $>4.2$ are not desirable, even with high technology. Moreover, values $<3.8$ in unfavorable environments are not desirable either. This is because cotton with low micronaire is often immature and prone to breakage during processing, and higher micronaire does not lead to spinning of fine textiles (Bourland et al., 2010; Freire, 2015).

Fiber quality traits are fundamental to the efficiency and profitability of the textile industry. The identification of

Table 3. Estimate of adaptability and stability $\left(P_{j}\right)$ of 12 cotton genotypes by the Lin and Binns (1988) method, as modified by Carneiro (1998), for fiber yield, for the total set of environments, and for favorable and unfavorable environments.

\begin{tabular}{|c|c|c|c|c|}
\hline Genotype & Overall mean & General $P_{i}$ & Favorable $P_{i}$ & Unfavorable $P_{i}$ \\
\hline & $\mathrm{kg} \mathrm{ha}^{-1}$ & & $-\times 1000.000$ & 2 \\
\hline TMG 41 WS & 1697 & 1.27 & 1.24 & 1.30 \\
\hline TMG 43 WS & 1684 & 1.29 & 1.36 & 1.20 \\
\hline IMA CV 690 & 1952 & 0.89 & 0.79 & 1.04 \\
\hline IMA 5675 B2RF & 1691 & 1.28 & 1.38 & 1.14 \\
\hline IMA 08 WS & 1765 & 1.18 & 1.35 & 0.95 \\
\hline NUOPAL & 1646 & 1.33 & 1.34 & 1.33 \\
\hline DP 555 BGRR & 1900 & 0.96 & 0.81 & 1.18 \\
\hline DELTA OPAL & 1654 & 1.34 & 1.18 & 1.55 \\
\hline BRS 286 & 1733 & 1.20 & 1.18 & 1.23 \\
\hline BRS 335 & 1689 & 1.29 & 1.16 & 1.47 \\
\hline BRS 368 RF & 1774 & 1.14 & 1.10 & 1.20 \\
\hline BRS 369 RF & 1818 & 1.08 & 0.92 & 1.30 \\
\hline
\end{tabular}

Table 4. Estimate of adaptability and stability $\left(P_{j}\right)$ by the Lin and Binns (1988) method, as modified by Carneiro (1998), for the fiber length of 12 cotton genotypes, for the total set of environments, and for favorable and unfavorable environments.

\begin{tabular}{|c|c|c|c|c|}
\hline Genotype & Overall mean & General $P_{i}$ & Favorable $P_{i}$ & Unfavorable $P_{i}$ \\
\hline & $\mathrm{mm}$ & & & \\
\hline TMG 41 WS & 29.14 & 8.98 & 9.31 & 8.52 \\
\hline TMG 43 WS & 29.30 & 8.28 & 8.45 & 8.05 \\
\hline IMA CV 690 & 29.37 & 8.08 & 8.48 & 7.52 \\
\hline IMA 5675 B2RF & 29.39 & 7.97 & 7.26 & 8.95 \\
\hline IMA 08 WS & 31.04 & 2.95 & 2.91 & 3.00 \\
\hline NUOPAL & 30.20 & 5.03 & 5.02 & 5.04 \\
\hline DP 555 BGRR & 29.51 & 7.45 & 6.92 & 8.17 \\
\hline DELTA OPAL & 29.77 & 6.52 & 6.68 & 6.31 \\
\hline BRS 286 & 29.84 & 6.44 & 5.64 & 7.54 \\
\hline BRS 335 & 30.46 & 4.29 & 4.41 & 4.12 \\
\hline BRS 368 RF & 29.51 & 7.43 & 7.00 & 8.02 \\
\hline BRS 369 RF & 30.09 & 5.40 & 4.93 & 6.04 \\
\hline
\end{tabular}


cotton genotypes with high stability for traits related to fiber quality provides a more uniform product that fetches better prices to cotton producers at cotton lot negotiations. The present results also assist parent selection strategies for crosses in a breeding program. For instance, the genotype BRS 335, which has a high mean FL and suitable micronaire, can be crossed with genotypes TMG 41 WS and DELTA OPAL, which have high FS, since much of the underlying trait genetic variability is additive. However, the genetic diversity among these genotypes must be evaluated so as not to restrict the variability in segregating populations.

It is important to note that for all evaluated traits, with the exception of micronaire, the genotypic mean was negatively correlated with the estimates of $P_{i}$ (general, favorable, and unfavorable). This indicates that the genotypes with the highest trait genotypic mean were also the most suitable (low $P_{i}$ ) across environments. The exception was micronaire, where an intermediate value is most desirable.

\section{Multivariate Adaptability and Stability}

The Lin and Binns (1988) method, as modified by Carneiro (1998), was used in a multivariate context (Table 7) to recommend genotypes that have high adaptability and stability for all evaluated traits simultaneously. Weights were established for the traits, based on the degree of importance of each trait for the Brazilian cotton producer and the textile industry (Freire, 2015). However, only the
Table 7. Estimate of multivariate adaptability and stability $\left(P_{i}\right)$ of 12 cotton genotypes by the Lin and Binns (1988) method, as modified by Carneiro (1998), for fiber yield, fiber length, fiber strength, and micronaire for the total set of environments.

\begin{tabular}{lc}
\hline Genotype & General $P_{i}$ \\
\hline TMG 41 WS & 9.13 \\
TMG 43 WS & 8.14 \\
IMA CV 690 & 9.46 \\
IMA 5675 B2RF & 8.73 \\
IMA 08 WS & 5.90 \\
NUOPAL & 6.53 \\
DP 555 BGRR & 8.73 \\
DELTA OPAL & 7.34 \\
BRS 286 & 7.16 \\
BRS 335 & 6.15 \\
BRS 368 RF & 8.24 \\
BRS 369 RF & 8.22 \\
\hline
\end{tabular}

recommendation in a generalized way for the multiple traits evaluated was performed, since a favorable environment for FY may not be favorable for the other traits and vice versa.

Given the analysis, the genotypes IMA 08 WS and BRS 335 have the best combination of desirable traits, since they had the lowest estimates of $P_{i}$ in the multivariate context. The identification of genotypes that have adaptability and stability for multiple traits is fundamental for cotton breeding programs, since it will assist in the selection strategies and recommendation. Studies on the $\mathrm{G} \times \mathrm{E}$ interaction in a multivariate context are still scarce. Nevertheless, these studies are extremely relevant

Table 5. Estimate of adaptability and stability $\left(P_{j}\right)$ by the Lin and Binns (1988) method, as modified by Carneiro (1998), for fiber strength of 12 cotton genotypes, for the total set of environments, and for favorable and unfavorable environments.

\begin{tabular}{|c|c|c|c|c|}
\hline Genotype & Overall mean & General $P_{i}$ & Favorable $P_{i}$ & Unfavorable $P_{i}$ \\
\hline & gf tex ${ }^{-1}$ & & & \\
\hline TMG 41 WS & 32.02 & 16.66 & 15.58 & 18.14 \\
\hline TMG 43 WS & 30.82 & 23.78 & 21.99 & 26.23 \\
\hline IMA CV 690 & 31.01 & 23.18 & 25.30 & 20.27 \\
\hline IMA 5675 B2RF & 28.82 & 39.55 & 38.78 & 40.61 \\
\hline IMA 08 WS & 29.89 & 30.12 & 28.70 & 32.08 \\
\hline NUOPAL & 30.89 & 22.99 & 24.22 & 21.31 \\
\hline DP 555 BGRR & 28.80 & 39.24 & 41.00 & 36.82 \\
\hline DELTA OPAL & 31.84 & 16.94 & 16.70 & 17.26 \\
\hline BRS 286 & 30.33 & 27.15 & 24.69 & 30.53 \\
\hline BRS 335 & 29.84 & 30.54 & 30.00 & 31.27 \\
\hline BRS 368 RF & 29.47 & 33.62 & 34.54 & 32.35 \\
\hline BRS 369 RF & 30.03 & 29.74 & 28.37 & 31.61 \\
\hline
\end{tabular}

Table 6. Estimate of adaptability and stability $\left(P_{i}\right)$ by the Lin and Binns (1988) method, as modified by Carneiro (1998), for the micronaire of 12 cotton genotypes, for the total set of environments, and for favorable and unfavorable environments.

\begin{tabular}{|c|c|c|c|c|}
\hline Genotype & Overall mean & General $P_{i}$ & Favorable $P_{i}$ & Unfavorable $P_{i}$ \\
\hline TMG 41 WS & 4.39 & 0.17 & 0.30 & 0.06 \\
\hline TMG 43 WS & 4.24 & 0.09 & 0.17 & 0.04 \\
\hline IMA CV 690 & 4.53 & 0.23 & 0.39 & 0.08 \\
\hline IMA 5675 B2RF & 3.97 & 0.07 & 0.10 & 0.03 \\
\hline IMA 08 WS & 4.31 & 0.12 & 0.21 & 0.04 \\
\hline NUOPAL & 4.18 & 0.10 & 0.16 & 0.06 \\
\hline DP 555 BGRR & 4.19 & 0.11 & 0.17 & 0.05 \\
\hline DELTA OPAL & 4.36 & 0.13 & 0.25 & 0.04 \\
\hline BRS 286 & 4.24 & 0.08 & 0.13 & 0.04 \\
\hline BRS 335 & 4.16 & 0.07 & 0.12 & 0.03 \\
\hline BRS 368 RF & 4.21 & 0.09 & 0.13 & 0.05 \\
\hline BRS 369 RF & 4.48 & 0.20 & 0.35 & 0.06 \\
\hline
\end{tabular}


for cotton breeding, since the selection of this species is performed based on multiple traits of interest.

\section{CONCLUSIONS}

The recommendation of genotypes considering multivariate adaptability and stability differs from that of individual traits. The multivariate method identified that the genotypes IMA 08 WS and BRS 335 have the best combination of desirable traits.

The evaluation of the agronomic performance of genotypes in tropical regions, such as the Brazilian Cerrado, is crucial for cotton breeding programs, since it supports the recommendations for groups of environments. It optimizes crossing strategies when using genotypes that have high yield, desirable fiber traits, wide adaptability, and high stability.

\section{Conflict of Interest}

The authors declare that there is no conflict of interest.

\section{Supplemental Material Available}

Supplemental material is available online for this article.

\section{References}

Amorim, E.P., C.E.O. Camargo, A.W.P. Ferreira Filho, A.P. Junior, P.B. Gallo, and J.A. Azevedo Filho. 2006. Adaptabilidade e estabilidade de linhagens de trigo no Estado de São Paulo. Bragantia 65:575-582. doi:10.1590/S0006-87052006000400007

Bauer, P.J., J.R. Frederick, J.M. Bradow, E.J. Sadler, and D.E. Evans. 2000. Canopy photosynthesis and fiber properties of normal- and late-planted cotton. Agron. J. 92:518-523. doi:10.2134/agronj2000.923518x

Baxevanos, D., C. Goulas, J. Rossi, and E. Braojos. 2008. Separation of cotton cultivar testing sites based on representativeness and discriminating ability using GGE biplots. Agron. J. 100:1230-1236. doi:10.2134/agronj2007.0363

Blanche, S.B., and G.O. Myers. 2006. Identifying discriminating locations for cultivar selection in Louisiana. Crop Sci. 46:946-949. doi:10.2135/cropsci2005.0279

Bourland, F.M., H. Hogan, D.C. Jones, and E. Barnes. 2010. Development and utility of Q-score for characterizing cotton fiber quality. J. Cotton Sci. 14:53-63.

Carvalho, L.P., F.J.C. Farias, and J.I.S. Rodrigues. 2015. Estabilidade e adaptabilidade de genótipos de algodão de fibra colorida quanto aos caracteres de fibra. Cienc. Rural 45:598-605. doi:10.1590/0103-8478cr2013023

Campbell, B.T., and M.A. Jones. 2005. Assessment of genotype $\times$ environment interactions for yield and fiber quality in cotton performance trials. Euphytica 144:69-78. doi:10.1007/s10681005-4336-7

Carneiro, P.C.S. 1998. Novas metodologias de análise da adaptabilidade e estabilidade de comportamento. Ph.D. diss., Univ. Fed. Viçosa, Viçosa, Minas Gerais, Brazil.

Conab (Companhia Nacional de Abastecimento). 2017. Acompanhamento de Safra Brasileira: Grãos, décimo segundo levantamento, Agosto/2017. Conab. http://www.conab.gov.br (accessed 10 Aug. 2017).

Cruz, C.D. 2013. GENES: A software package for analysis in experimental statistics and quantitative genetics. Acta Sci. Agron. 35:271-276. doi:10.4025/actasciagron.v35i3.21251
Cruz, C.D., A.J. Regazzi, A.J. Carneiro, and P.C. Souza. 2012. Modelos biométricos aplicados ao melhoramento genético. Univ. Fed. Viçosa, Viçosa, Minas Gerais, Brazil.

Cruz, C.D., R.D. Torres, and R. Vencovsky. 1989. An alternative approach to the stability analysis proposed by Silva and Barreto. Rev. Bras. Genet. 12:567-580.

Farias, F.J.C., L.P. Carvalho, J.L. Silva Filho, and P.E. Teodoro. 2016. Correlations and path analysis among agronomic and technological traits of upland cotton. Genet. Mol. Res. 15:Gmr.15038239. doi:10.4238/gmr.15038239

Finlay, K.W., and G.N. Wilkinson. 1963. The analysis of adaptation in a plant-breeding programme. Aust. J. Agric. Res. 14:742-754. doi:10.1071/AR 9630742

Franceschi, L., G. Benin, V.S. Marchioro, T.N. Martin, R.R. Silva, and C.L. Silva. 2010. Métodos para análise de adaptabilidade e estabilidade em cultivares de trigo no estado do Paraná. Bragantia 69:797-805. doi:10.1590/S0006-87052010000400004

Freire, E.C.F. 2015. Algodão no cerrado do Brasil. Assoc. Bras. Produtores Algodão, Brasília.

Gilio, T.A.S., D.V. Araújo, W. Krause, H.H.R. Rosa, and J.P. Ascari. 2017. Genetic divergence among cotton genotypes grown in the main crop season and off season. Rev. Caatinga 30:377-390. doi:10.1590/1983-21252017v30n213rc

Lin, C.S., and M.R. Binns. 1988. A superiority measure of cultivar performance for cultivar $\times$ location data. Can. J. Plant Sci. 68:193-198. doi:10.4141/cjps88-018

Murakami, M.D., A.A. Cardoso, C.D. Cruz, and N. Bizão. 2004. Considerações sobre duas metodologias de análise de estabilidade e adaptabilidade. Cienc. Rural 34:71-78. doi:10.1590/ S0103-84782004000100011

Ng, E.H., K. Jernigan, W. Smith, E. Hequet, J. Dever, S. Hague, and A.M.H. Ibrahim. 2013. Stability analysis of upland cotton in Texas. Crop Sci. 53:1347-1355. doi:10.2135/cropsci2012.10.0590

Pimentel-Gomes, F. 2009. Curso de estatística experimental. 15th ed. Fund. Estudos Agrár. Luiz de Queiroz, Piracicaba, São Paulo, Brazil.

Reddy, V.R., D.N. Baker, and H.F. Hodges. 1991. Temperature effects on cotton canopy growth, photosynthesis, and respiration. Agron. J. 83:699-704. doi:10.2134/agronj1991.0002196 2008300040010x

Silva Filho, J.L., C.L. Morello, F.J.C. Farias, F.M. Lamas, M.E. Pedrosa, and J.L. Ribeiro. 2008. Comparação de métodos para avaliar a adaptabilidade e estabilidade produtiva em algodoeiro. Pesq. Agropec. Bras. 43:349-355.

Souza, A.A., E.C. Freire, R.L.A. Bruno, and L.P. Carvalho. 2006. Estabilidade e adaptabilidade do algodoeiro herbáceo no Cerrado do Mato Grosso e Mato Grosso do Sul. Pesqui. Agropecu. Bras. 41:1125-1131. doi:10.1590/S0100204X2006000700008

Suinaga, F.A., C.S. Bastos, and L.E. Pacifici Rangel. 2006. Phenotypic adaptability and stability of cotton cultivars in Mato Grosso State, Brazil. Pesqui. Agropecu. Trop. 36:145-150.

USDA-AMS. 2001. The classification of cotton. Agric. Handb. 566. USDA, Agric. Marketing Serv., Washington, DC.

Verma, M.M., G.S. Chahal, and B.R. Murty. 1978. Limitations of conventional regression analysis a proposed modification. Theor. Appl. Genet. 53:89-91. doi:10.1007/BF00817837

Xu, N., M. Fok, J. Li, X. Yang, and W. Yan. 2017. Optimization of cotton variety registration criteria aided with a genotype-bytrait biplot analysis. Sci. Rep. 7:17237. doi:10.1038/s41598017-17631-4 